\title{
CONTEXTUALIZAÇÃO DA TABOCA NO CENÁRIO ATUAL DA COMIDA DE RUA EM SALVADOR/BA
}

\author{
Laís Conceição Portela ${ }^{1}$ \\ Virgínia Campos Machado ${ }^{2}$
}

\section{INTRODUÇÃO ${ }^{3}$}

Sendo um dos símbolos mais conhecidos e presentes na comida de rua de Salvador, a taboca é uma guloseima de características únicas, produzida de forma artesanal e basicamente composta por farinha de trigo, água e açúcar. Crocante de espessura fina e formato cilíndrico, o biscoito é comercializado em vários pontos de Salvador há muito tempo, fazendo parte do cotidiano da cidade (Poro, 2014a; Aragão 2011a).

Visto como um elemento comum soteropolitano, a comida de rua é diretamente influenciada pela formação de Salvador, presente nas histórias, se mantendo, se adaptando e se ressignificando, resistindo a urbanização e globalização da cidade. A formação da capital baiana sempre interagiu com sua cultura, tornando-se impossível se limitar aos conceitos e denominações.

Tendo diversas definições ao longo dos anos, a Cidade possui um grande leque de conceitos, sendo estes positivos, negativos, subjetivos ou geográficos. Na década de 30 esta obtém uma concepção objetiva e ampla que reside na relação de diversos aspectos. Segundo Lewis Mumford, no livro A Cultura das Cidades (1938), a cidade é definida como um encadeamento geográfico e econômico que concentra cultura e herança social, possibilitando a interação das atividades entre a população. Em 1994, Milton Santos, apresenta sobre estas características, um contraponto entre a cidade (particular, concreto e interno) e o urbano (abstrato, geral e externo), afirmando então a complexidade que é definir a cidade (Vasconcelos, 1999a).

Quando se observa a expansão da cidade e a influência sobre a cultura e economia desta, é possível afirmar que a urbanização é um dos principais fatores que

\footnotetext{
${ }^{1}$ Universidade Federal da Bahia, Brasil. Email: 1.porteela@hotmail.com ORCID id: https://orcid.org/0000-0002-3820-934X

${ }^{2}$ Universidade Federal da Bahia, Brasil. Email: virginia.campos@ufba.br ORCID id: https://orcid.org/0000-0003-3568-7343

${ }^{3}$ Este texto deriva do trabalho de conclusão de curso: Contextualização de Taboca no Cenário Atual da Comida de Rua de Salvador-Ba, realizado no ano de 2016.
} 
modifica diretamente o comércio e transforma-o na produção social de diversificação de culturas presentes e suas relações (Vasconcelos, 1999b; Graham, 2013). O principal comércio que exprime diretamente a cultura da população e incentiva a interação entre os membros da cidade é a comercialização comida de rua, atividade esta que dialoga com o público, as crenças, o urbano e a própria cidade (Leal, 2014).

No Brasil a comercialização de alimentos nas ruas é uma das práticas mais antigas, comumente utilizada pelos grupos excluídos da economia formal. Na Bahia a comercialização de alimentos nas ruas se iniciou a partir do séc. 18, denominada como atividades de escravos de ganho, que saiam vendendo quitutes de origens africanas, europeias e asiáticas na cidade de Salvador (Santos, 2011a).

Definida por um conjunto de alimentos e bebidas que são comercializados por ambulantes em locais de acesso ao público (Pertile, 2013), a comida de rua seguiu a evolução da cidade e logo passou a significar a oferta de acordo com a urbanização de Salvador. Desta maneira conferiu tradição e cultura ocupando novos espaços da cidade e fazendo parte do cotidiano (Santos, 2011b).

Conhecida por suas expressões, a comida de rua soteropolitana é comumente preparada de forma artesanal e em pequena escala e ressalta a necessidade do estímulo para sua valorização cultural que se manifesta e ocupa a memória dos moradores da cidade (Poro, 2014b).

Como símbolo da comida de rua de Salvador, a taboca e sua comercialização na cidade exprime o diálogo entre a cultura, alimentação e o desenvolvimento urbano soteropolitano. Diante disto, para a compreensão da comercialização, significações e caracterização do produto torna-se necessária contextualização da taboca no cenário atual da comida de rua de Salvador.

\section{CONSIDERAÇÕES SOBRE A TABOCA, SEU HISTÓRICO E ORIGEM.}

Muito conhecida no Nordeste, a taboca, recebeu várias nomenclaturas e classificações desde sua chegada ao Brasil (Aragão, 2011b). De suposta origem espanhola, vestígios apontam que sua produção se iniciou no cristianismo com intuito de distribuir à fieis em substituição ao pão divino. A receita entretanto, foi peregrinando 
pelos mosteiros e sendo modificada de acordo com as oficinas ${ }^{4}$, servida apenas em congregações e só posteriormente ao público. Conhecido na Espanha como Barquillos, o produto era direcionado a datas festivas, podendo ser encontrado em diversas padarias de Madrid, sendo recheados ou não (Aragão, 2013a; Polén Artesanas, 2016a).

Além da Espanha, em Portugal o produto também é conhecido e consumido, denominado Barquilho. Nos Estados Unidos, o famoso biscoito também é consumido, porém sendo facilmente confundido com os Wafers. Estando em diversas culturas no mundo e revelando significados diferentes, os ingredientes básicos da taboca se assemelham na maioria das produções (Aragão, 2013b; Polén Artesanas, 2016b).

Os primeiros indícios de taboca no território brasileiro foram em Alagoas no ano de 1950. Provavelmente trazida pelos europeus, o quitute ${ }^{5}$ foi se disseminando pelo litoral nordestino, região onde há maior facilidade de encontrá-lo. Em Fortaleza/CE a taboca também é conhecida, sendo denominada de como chegadinho. Em outros estados brasileiros o produto pode ser identificado como cavaco e biju (em Recife e João Pessoa), ou cavaco-chinês (em Natal) (Aragão, 2011c; Aragão, 2013c).

Com uma diversidade incrível, chegando até o sul do país, a taboca também se modifica na sua forma de venda de acordo com a região. A musicalidade é uma característica inerente a venda de taboca, cujo conforme o local pode-se encontrar desde o triângulo à zabumba, ambos instrumentos da cultura nordestina, o que enfatiza a peregrinação da iguaria pela região (Aragão, 2009a).

$\mathrm{Na}$ Bahia, a denominação do biscoito tem ligação direta com os povos indígenas. De origem tupi, taboca significa bambu, o que relaciona o formato do biscoito à planta. Sem padronização na formulação, no território baiano encontra-se taboca produzida desde a farinha de mandioca e farinha de trigo, até indícios do uso da farinha láctea, além do acréscimo de elementos enriquecedores como: leite, ovos e margarina (Filgueiras, Gonçalves, 2007; Aragão, 2013d).

A venda de taboca na cidade de salvador é anunciada, tradicionalmente, pelo vendedor através do triângulo. A guloseima é embalada em um saco plástico, geralmente em quatro unidades e transportada pelo ambulante em um recipiente formado pela junção

\footnotetext{
${ }^{4}$ Lugar onde se elabora, fábrica ou conserta algo.

${ }^{5}$ Nome dado à um alimento saboroso, geralmente de características doces.
} 
de duas latas de tinta, personalizada com o nome taboca em letras garrafais (Poro, 2014c; Aragão, 2009b).

Podemos perceber que diversas relações são estabelecidas por meio do preparo, da venda e do consumo de taboca. Ainda que esta seja conhecida e consumida em tempos e espaços diferentes, seus significados e representações transmitem aspectos referentes a tradição e a comensalidade.

\section{METODOLOGIA}

Esta pesquisa trata-se de um estudo qualitativo realizado em Salvador/BA cujo participantes foram setenta e nove consumidores e/ou conhecedores da taboca e um vendedor do produto. Empregou-se dois tipos diferentes de instrumentos de produção de dados: para os consumidores foram aplicados questionários elaborados e preenchidos de forma online com assuntos referentes aos aspectos históricos culturais da taboca e para o vendedor realizou-se uma entrevista semiestruturada sobre o cotidiano do comércio do quitute. Os dados foram analisados conforme o método de Análise de Conteúdo de Bardin (1971), técnica utilizada para analisar dados qualitativos através de procedimentos sistemáticos e objetivos para descrição do conteúdo.

\section{RESULTADOS}

\section{Mapeamento dos vendedores e produtores de Taboca em Salvador}

O mapeamento dos pontos de venda da Taboca foi computado a partir de dados do questionário e da entrevista com o vendedor, no intuito de identificar os tipos de vendedores presentes na cidade de Salvador (tradicionais e ambulantes comuns). Foram mapeados 19 diferentes pontos de venda de Taboca, sendo ainda citados locais como praia e estação de trem que, apesar de não permitirem a identificação geográfica exata dão conta da peregrinação dos vendedores que contribui para que o produto alcance diversas regiões da cidade. 
Figura 1 - Mapa dos vendedores de Taboca em Salvador/Ba
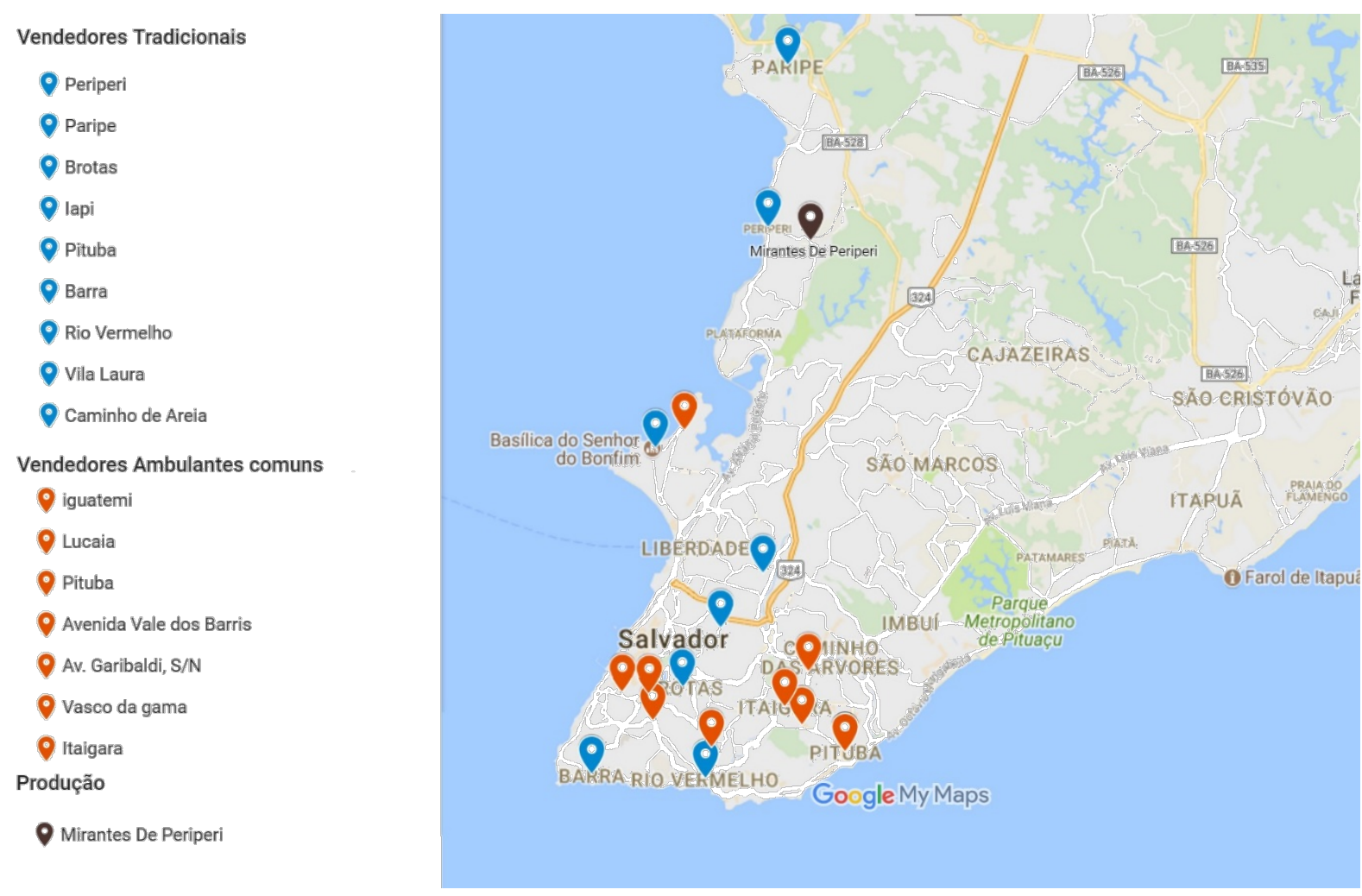

Imagem produzida pela autora via Google Maps

De acordo com a relação de locais mapeados (figura 1), observa-se, que há uma concentração dos vendedores ambulantes na região do centro histórico e na região empresarial. Já em relação aos vendedores tradicionais, não ocorre uma concentração e observa-se que estes estão distribuídos, majoritariamente, entre os bairros residenciais da cidade.

Essa observação leva a percepção que os vendedores que demandam maior necessidade de adaptação ao cotidiano da cidade, vendem o produto distante do que é visto tradicionalmente na cidade e se concentram principalmente em áreas mais comerciais. Enquanto os vendedores tradicionais, que ainda portam instrumentos de identificação da venda de taboca, mantêm suas vendas em locais residenciais onde o desenvolvimento urbano comercial não atua de forma expressiva. Afirmando o que é citado por Santos (2011c) em que a influência que ocorre através da expansão da cidade em termos de globalização, comércio e urbanização - afeta a alimentação social.

\section{A comercialização da Taboca em Salvador}


Durante a análise das informações foram encontrados indícios das mudanças na forma de venda da Taboca em Salvador, que podem estar relacionados diretamente com a urbanização da cidade e a necessidade de evolução dos ambulantes a estas mudanças. Como é mencionado por Santos (2011d), os ambulantes tiveram a necessidade de se adequar a "modernidade alimentar" que influenciou o comércio informal introduzindo produtos industrializados, que eram comercializados apenas em estabelecimentos formais, tomando espaço dos produtos mais tradicionais.

Segundo os dados coletados por meio do questionário, respondido por consumidores do doce, apenas 34,2\% $(n=27)$ referiram encontrar frequentemente vendedores de taboca nas ruas de Salvador.

Na entrevista realizada com João (nome fictício), vendedor de Taboca, questionouse sobre o modo de comercialização da guloseima. Sobre esse assunto, ele respondeu que realiza a venda do mesmo modo empregado para outros produtos, como se pode observar na fala abaixo:

[...] é você sabe, na verdade, eu trabalho de tudo, eu sou vendedor ambulante, eu trabalho dentro dos ônibus, vendendo queimado, vendendo essas coisas, vendendo chocolate. Ai a taboca, mais ou menos, a taboca é mais leve, e, é mais leve e eu trabalho mais no sinal, né? [João]

O relato do participante reafirma o que é mencionado por Poro (2014d) ao declarar que a comercialização da taboca na cidade soteropolitana era feita principalmente da forma tradicional, mas, com o passar dos anos, sofreu alterações significativas, a exemplo da comercialização no trânsito

Durante a entrevista, João relata que realiza a venda da Taboca da forma tradicional - utilizando o latão e o triângulo - mas somente aos finais de semana. Nos dias úteis, trabalha nos sinais de trânsito na região próxima ao centro histórico. A dinâmica do comércio nas sinaleiras da cidade exige agilidade, praticidade e facilidade de locomoção. Com isso, as tabocas são preferidas para a venda por serem "leves" e são dispostas em um cesto.

Verificou-se que a forma de comercialização do produto em sinais, interfere no seu reconhecimento pelo consumidor, desta maneira podemos afirmar como a cidade e sua urbanização influencia na cultura da venda e consumo do quitute. Nesse sentido, João afirma que muitas pessoas já conhecem o produto, mas que há dificuldade de 
reconhecimento quando este é vendido deste modo. Nessas ocasiões ele, por vezes, precisa explicar ao consumidor o que está vendendo e para os possíveis clientes que não conhecem o produto, cita alguns dos ingredientes utilizados na tentativa de promover a venda. Tudo isso se relaciona à ausência dos instrumentos tradicionais da comercialização da taboca pois, quando estes estão presentes, a relação consumidor-vendedor é profundamente modificada.

Observa-se que a sonoridade é um fator ligado diretamente ao produto, segundo Viviane Verdana (2010a), o som tem uma dimensão simbólica e de potencialização de narrativa, produzindo referências que exprimem sentimentos, emoções e afetividade. E isto é reproduzido ao tocar o triângulo, há um reconhecimento do produto pelo consumidor e melhora a venda. Diferente do que acontece quando a comercialização é feita no sinal de trânsito, o triângulo é quem apresenta a Taboca ao consumidor, dispensando explicação pelo comerciante.

[...] na lata já tem os clientes (...) aí já está ligado, vê batendo o triângulo ali, ai o pessoal já vê que é taboca[...] [João]

“(...) além de entender o som como um fenômeno da cultura, conforme aponta Michel Chion (2004) podemos compreendê-lo também como imagem simbólica (Durand, 1968). 0 som, neste caso, tomado do ponto de vista da representação, não se limita a ser índice ou signo, mas símbolo pertencente ao contexto mais amplo da cultura e suas formas de expressão sonora (...)" (Verdana, 2010b)

A mudança na forma de apresentação do produto faz com que a taboca, pouco reconhecida nos dias úteis, torne-se um produto cobiçado pela clientela aos finais de semana. O som do triângulo e a lata decorada permitem que a taboca seja reconectada ao seu histórico e à tradição, assim como às histórias individuais dos consumidores.

O sabor, amigos, família e atualmente o gostinho da infância. (Consumidor)

Outro aspecto a salientar é que a modificação na relação de venda parece interferir na própria satisfação do vendedor com o próprio trabalho, como pode-se inferir a partir da fala de João quando declara ter preferência pela venda aos finais de semana:

[...] às vezes o pessoal está no bar ali tomando cerveja, ali chama pra comprar. Chama para dar aos meninos. Aí, sábado, é por isso que gosto de vender dia de sábado na lata, sábado e domingo. [...] [João] 
Semelhante ao que Aragão (2011d) aponta em relação aos consumidores do Ceará, em Salvador também existe essa assimilação do triângulo no comércio da taboca. A clientela cearense reconhece facilmente os vendedores pelo som emitido pelo triângulo e quando este não é utilizado surge o questionamento por parte do consumidor sobre a origem do produto. Tal fato permite concluir que fatores externos modificam a venda da taboca, podendo contribuir ou limitar a valorização da taboca.

Apesar de o entrevistado mencionar que se vende mais aos sábados e domingos, ele não identifica uma época em que seja mais rentável vender taboca. João afirma que, em relação às épocas festivas do ano, em Salvador, a venda não varia. Este resultado difere do que é encontrado em outros lugares onde o consumo do produto também é comum, como na Espanha, onde o Barquillo é mais consumido em épocas festivas, principalmente no Natal (Aragão, 2013e).

\section{Ingredientes e Modo de Preparo}

Considerado, pelos consumidores e pelo vendedor, um produto tradicional da comida de rua soteropolitana, a taboca traz consigo a incógnita da sua composição e da forma de preparo. Durante a pesquisa o vendedor e os consumidores citam diversos ingredientes que acreditam compor a taboca. Muitos dos ingredientes citados se assemelham aos presentes na literatura, como é o caso da farinha de trigo, açúcar, água e dos derivados da mandioca. Aragão (2011e) descreve que o chegadinho, nome que a taboca recebe no Ceará, é produzido com esses mesmos ingredientes.

Nessa pesquisa não foi possível consultar nenhum produtor dessa guloseima, o que impede que sejam feitas reflexões sobre possíveis variações nos ingredientes ou modo de preparo. No entanto, a referência pelos participantes da pesquisa, existem ingredientes muito distintos da literatura, o que chama a atenção. Foram citados ingredientes como farinha láctea, leite, coco e baunilha. A utilização de alguns destes no preparo da taboca é pouco provável, como é o caso da farinha láctea e da baunilha, tendo em vista o valor de venda da taboca, segundo citado pelo vendedor:

[...] eu vendo no sinal, vendo uma é quatro, três é dez. Na minha mão, um é quatro, três é dez. Às vezes o cliente chora, eu faço três reais, quando dá eu faço três. [...] [João] 
Como forma de preparo, o vendedor informou que todos os ingredientes são batidos e, depois, colocados para assar em um equipamento específico, nomeado apenas como máquina. Aragão (2011f, 2013f) descreve que este doce é assado em chapas sobre fornos a carvão e que alguns produtores possuem prensa mas que os mesmos, assim como João, se referem ao instrumento como máquinas.

As considerações sobre as falas de João sobre o preparo da taboca levam em conta que o vendedor ambulante não é o produtor deste doce, mas pode conhecer o processo de preparo por obter a mercadoria com uma produtora artesanal. Questionado sobre o porquê de não produzir taboca, o vendedor afirma que é um trabalho muito árduo, como mostra abaixo:

[...] eu não tenho condições de fazer não, tenho que comprar máquina, é comprar máquina. Muita dor de cabeça fazer aquilo ali. Tem que acordar cedo. O pessoal às vezes acorda três horas da manhã para fazer (...) acorda três horas da manhã para fazer

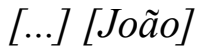

Diante do comentário acima se pode reafirmar o que é encontrado na literatura, que pessoas que se propõem a produzir a taboca têm um trabalho redobrado, pois além de acordar na madrugada para fazer e embalar a taboca, precisa sair à rua para vender. Ainda assim, aqueles que acumulam as funções de produtor e vendedor consideram que a autonomia compensa (Aragão, 2013g). Perante esta análise, é possível questionar uma suposta a redução dos produtores de Taboca, em Salvador que por mais que haja a compensação na autonomia da produção e venda, ainda há os que preferem se manter na terceirização do produto, ressaltando a falta de condições para produção.

\section{As significações do produto para quem comercializa e consome}

A taboca é um produto afetivo da comida de rua de Salvador e traz consigo cultura, história e sabor (Poro, 2014e). Em relação às significações da taboca para quem a vende e quem a consome, as falas produzidas durante a entrevista com o vendedor evidenciam a importância da guloseima (para ele e para os consumidores) e sua expressão no modo como a população reage ao ouvi-lo trazer a taboca:

[...] aí tem vezes que está lá dentro de casa, aí vê batendo o triângulo. Ai manda parar para comprar, manda eu esperar! [...] [João] 
[...] é de tradição das pessoas né? As pessoas gostam [...] [João]

[...] as coroas também gostam de comprar pra relembrar os velhos tempos de criança [...] [João]

Observando o dito pelo vendedor e também as respostas obtidas no questionário, percebemos que, para a população de Salvador, a taboca é um produto com aspectos familiares e lembranças importantes que são trazidas pelo som emitido pelo triângulo e pelo seu sabor.

Segundo Garcia (1994), assim como a cultura social pode ser motivada pelo ambiente físico da cidade, a alimentação urbana da população pode ser incentivada por fatores externos como valores, acesso e praticidade e também pelo prazer, fome ou afetividade. Pesquisas de caracterização do consumidor do comércio informal alimentício de Salvador, afirma-se que a maioria destes iniciam o consumo durante a infância (Santos, 2011e), como foi observado nos dados coletados dos consumidores de Taboca em Salvador.

A partir das respostas ao questionário foi possível perceber que o incentivo ao consumo do produto foi dado principalmente por pais $(57,1 \%)$ e avós $(24 \%)$, seguidos de vendedor $(9,5 \%)$, amigos $(4,7 \%)$ e outros $(4,7 \%)$. A apresentação da taboca foi realizada pelos pais (44\%); vendedor (32\%); amigo (16\%), avós (8\%). Comumente as respostas sobre apresentação do produto e incentivo ao consumo vieram acompanhadas de relatos que trazem um teor de lembrança boa da infância, como:

"Como desde a infância sempre gostei, hoje tem um gostinho de saudade ainda melhor."

"É algo diferente e o som do sino chama atenção pra querer comer e como conheci pequena criança ama o som do sino."

"Ela é uma festa, começando pelo vendedor com sua indumentária e triângulo barulhento!"

Apesar dos consumidores trazerem em suas respostas lembranças familiares e memórias gustativas, as falas do comerciante não se referem à taboca como tradição ou elemento cultural, mas muito mais à necessidade financeira e de manter-se no mercado de trabalho:

[...] sim, é, significa sim, pra não ficar parado. [...] [João]

[...] é, eu trabalho com ela lá. Um negócio mais leve né? Eu saio pra vender, ganhar meu trocadinho. [...] [João] 
O que nos traz a indagação do porquê o vendedor não obtém, como os demais consumidores, referências mais afetivas. Para entender essa questão é preciso considerar como se dá o consumo da taboca por parte do vendedor, destacando que ele não toma conhecimento do produto como um alimento próprio para venda, como é o caso dos consumidores comuns, e sim de uma taboca considerada não vendável por conta da apresentação e/ou da estrutura que se encontra:

[...] consumia sim, pegava assim na mão dos meninos, comia, eles me davam, às vezes vinha quebrada, eles chegavam me dava, ai eu ia comendo gostei, aí eu peguei e aí comecei a revender. Ai vinham quebrada eles me davam o dono mesmo me dava: "tome aí, leve ai come ai". Ai eu comecei a pegar para revender na rua. [...] [João]

Portanto, nota-se que o contato inicial do vendedor pode ter afetado a primeira relação que o mesmo teve do produto, e traz a discussão do porquê talvez não haja, a partir do vendedor, a degustação do produto quando vem direto de seu produtor.

A partir disto, observa-se que o vendedor atribui um sentido para a taboca diferente dos consumidores, que remetem o produto à tradição e afetividade, enquanto o vendedor sempre aborda a taboca nas questões socioeconômicas ou ao consumo do produto que não é vendido. Ao falar sobre a sua relação com o produto ele não se encaixa na posição compartilhada pelos demais consumidores, mas a partir dos trechos podemos apreender elementos que o introduz na história e tradição das vendas de taboca em Salvador mesmo que o vendedor não tenha essa percepção.

\section{CONSIDERAÇÕES FINAIS}

Diante dos resultados encontrados conclui-se que a Taboca se mantém simbolicamente como um produto da comida de rua de Salvador, mas sua comercialização sofreu alterações por conta das mudanças comerciais e urbanas na cidade, intensificando necessidade de adaptação dos vendedores para se manter no mercado, modificando a venda de forma que facilita-se a locomoção com o produto principalmente em áreas mais comerciais. Entretanto ainda há a venda de forma tradicional com todos seus acessórios e sonoridade, mas é restrita aos dias ou locais específicos com maior número de residências e menos incidência nas áreas empresariais ou comerciais. 
Contextualizando a taboca no comércio de rua atual da cidade de Salvador, foi possível definir que a Taboca, para os seus consumidores, tem características diretamente ligadas às lembranças familiares e aspectos históricos da sua convivência com a cultura gastronômica soteropolitana, apesar da influência urbana na mudança cotidiana do mesmo o produto ainda traça aspectos afetivos e de cultura. Enquanto para o vendedor o produto se restringe às questões econômicas sociais, porém o mesmo tem a percepção da importância do produto para os consumidores, mas não possui a percepção do seu papel na preservação da Taboca como símbolo gastronômico cultural da cidade.

Contudo é possível afirmar que a cidade tem influência direta sobre as culturas que nela habita, sendo de forma física ou abstrata, principalmente em relação ao comer, onde os aspectos urbanos influenciam a alimentação dos seus conterrâneos.

Nessa pesquisa havia a intenção de entrevistar produtores de taboca, o que não foi viável. Desta maneira ocorre que não foi possível solucionar a incógnita em relação aos ingredientes utilizados na produção da taboca em Salvador. Essas dificuldades se deram pela indisponibilidade dos produtores diante da sua árdua rotina.

\section{REFERÊNCIAS}

ARAGÃO, Thaís Amorim. Chegadinho: Doce Paisagem Sonora. Florianópolis-SC, 2009. ARAGÃO, Thaís Amorim. Como vendedores de chegadinho usam o som em seus percursos urbanos. Curitiba-PR, 2011.

ARAGÃO, Thaís Amorim. O triângulo e o biscoito fino para as massas: reverberações culturais de uma prática ambulante. São Paulo, 2013.

BARDIN, Laurence. L' Analyse de Conremt. Edições 70 Lda, 1977.

FILGUEIRAS, Tarcísio, \& GONÇALVES, Ana Paula. Tupi-Guarani: Fonte de Informação sobre Bambus Nativos do Brasil. Brasília, 2007.

GRAHAM, Richard. Alimentar a cidade - Das vendedoras de rua à reforma liberal (Salvador, 1780 - 1860). Salvador - BA: Companhia das Letras, 2013. 
LEAL, Cristian Oliveira Benevides Sanches \& TEIXEIRA, Carmen Fontes de Souza. Comida de rua: um estudo crítico e multirreferencial em Salvador, BA - Brasil. Revista Visa em Debate: Sociedade, Ciência e Tecnologia,2(04) pp. (12-22). Salvador, 2014. MUMFORD, L. (1945) La Cultura de las Ciudades. Buenos Aires: (orig. 1938).

PERTILE, Krisciê. Comida de Rua: Relações Históricas e Conceituais. Revista Rosa dos Ventos, 5(2). pp. (301-310). Caxias do Sul, RS, 2013.

POLEN, Artesanas. Tradición y calidad. Disponível em: <www.galletaspolen.es>. Acessado em: mar. de 2016. Espanha, 2016.

PORO. Pequeno Guia Afetivo da Comida de Rua de Salvador. Salvador: $3^{\mathrm{a}}$ Bienal da Bahia. Salvador, Bahia, 2014.

SANTOS, Orlando Almeida dos. Dos cantos aos camelódromos: comércio de rua e territorialidade negra no centro antigo de Salvador. Salvador - BA, 2011

VASCONCELOS, Pedro de Almeida. A Cidade, O Urbano, O Lugar. Salvador - BA, 1999

VERDANA, Viviane. Diálogos entre a imagem visual e a imagem sonoral: a experiência de escritura do sonoro nos documentários etnográficos. Revista do Programa de Pósgraduação em Cinema e Audiovisual da Universidade Federal Fluminense, v. 1, n. 24. Rio de Janeiro, 2011.

Recebido 17/10/2019

Aprovado 11/12/2019 


\section{ANEXO 1 - ROTEIRO DE ENTREVISTA}

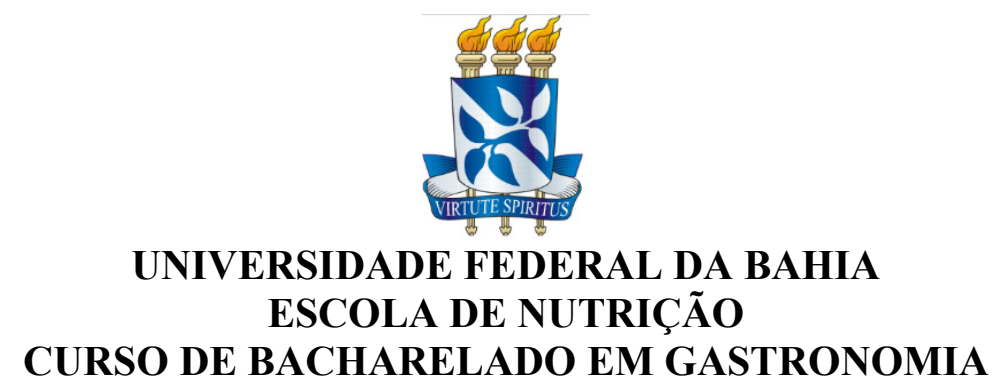

Projeto: Contextualização da Taboca no cenário atual da comida de rua em Salvador- Ba.

Roteiro de entrevista semi - estruturada para pesquisa qualitativa

Bloco I - Identificação do Entrevistado.

Nome:

Idade:

Endereço:

Naturalidade:

Estado Civil: $\quad$ Filhos:

Renda:

\section{Bloco II - Experiência social com a Taboca.}

- Como conheceu o produto? (quando, onde, algum histórico familiar?...)

- Consome o produto?

Se sim, Porque consome? Alguém incentivou no consumo? Gosta do produto?

Se não, Porque não consome? Já experimentou? Deixou de consumir?

- O produto significa algo para você? O que?

Bloco III - Experiência de Venda/Produção.

- Você produz a taboca que vende?

Se sim: Quais ingredientes utilizados? Onde aprendeu a fazer taboca? Há quantos anos produz? O que se usa para a produção (equipamentos e utensílios)? Sempre produziu assim? Gosta de produzir? Alguém influenciou a venda/produção? Como você faz Taboca?

Se Não: Onde Compra o produto que vende? Porque comprar lá? Porque não produz?

- Porque vender Taboca?

- Como você vende o produto? (utiliza instrumentos? alguma identificação?)

- Onde você costuma vender?

- Quem costuma comprar Taboca?

- Tem clientes fiéis? 
- Tem um período que se vende mais?

- Qual o valor do produto? (aumentou o valor com o tempo?)

- Da pra sustentar a família? (lucro?)

\section{Bloco IV - Distribuidoras.}

- Como produz o produto?

- Quais os ingredientes?

- Quais os equipamentos e utensílios?

- Há muita procura dos ambulantes de taboca?

- Qual o perfil dos ambulantes?

- Por que escolheu a taboca como produto de venda?

- Qual a média de distribuição do produto por mês?

- Qual o valor do produto em Atacado? E Varejo?

- Obtém lucro do produto?

- Quem idealizou distribuir o produto?

- Tem algum histórico com o produto?

- Consome ou já consumiu? 